\title{
Chapter 5 \\ Comparing the Risk Attitudes of Internationally Mobile and Non-Mobile Germans
}

\author{
Christiane Lübke, Jean P. Décieux, Marcel Erlinghagen, and Gert G. Wagner
}

\subsection{Introduction}

Moving particularly to a new country is a risky endeavour. People who choose to migrate are often thought to be more adventurous and risk-loving than their nonmobile counterparts. Robust empirical evidence on the risk attitudes of migrants is limited, however, particularly for migrants originating from high-income countries such as Germany. This study examines whether the risk attitudes of internationally mobile Germans ('movers') indeed differ significantly from those of their nonmobile counterparts ('stayers'), and whether significant differences can be observed in the risk attitudes of emigrants and remigrants. We also examine the effect of geographical and cultural distance between Germany and the destination country, predicting that it takes more courage to move to a more distant country.

Living and working abroad is becoming an increasingly important feature of individual careers at least in highly developed democratic welfare states (Erlinghagen et al. 2009). International mobility seems to be positively associated with increases in salaries (see Witte and Guedes Auditor 2021) and subjective well-being (see Guedes Auditor and Erlinghagen 2021). Some socio-economic and sociodemographic determinants of international mobility (e.g. education, gender; see Ette and Erlinghagen 2021) are also known to be general determinants of social inequality. If the propensity for international mobility is socially stratified, and if international mobility experiences independently increase individual life chances, international mobility may function as a catalyst for social inequality.

\footnotetext{
C. Lübke $(\bowtie) \cdot$ J. P. Décieux $\cdot$ M. Erlinghagen

Institute of Sociology, University of Duisburg-Essen, Duisburg, Germany

e-mail: christiane.luebke@uni-due.de; jean.decieux@uni-due.de; marcel.erlinghagen@ uni-due.de

G. G. Wagner

Max Planck Institute for Human Development, Berlin, Germany

e-mail: gwagner@mpib-berlin.mpg.de
} 
The decision to migrate and the choice of where to move is highly complex; it depends on a wide range of contextual and individual factors (Massey et al. 1994). In the economic literature, migration is generally conceptualised as an investment decision informed by the expected costs and benefits of migration (Massey et al. 1994; Sjaastad 1962). Migration from (and return migration to) high-income countries is not primarily driven by the aspiration to escape poverty and disadvantage (van Dalen and Henkens 2007). Socio-psychological approaches such as subjective expected utility (SEU; see Fischhoff et al. 1981; Fishburn 1981) and social production function theory (SPF; Lindenberg and Frey 1993; Ormel et al. 1999) broaden the perspective on the costs and benefits of migration to cover non-monetary aspects, including social and emotional determinants. Psychological determinants may also help to explain why some individuals decide to migrate while others do not. To date, however, little is known about the psychological determinants of international migration. Boneva and Frieze (2001) have argued that there is a kind of 'migrant personality' that differentiates those who leave their country from those who stay at home. Higher risk affinity may be one aspect of such a personality, with migrants being more adventurous and risk-loving than non-migrants. Against this background, this chapter aims to contribute to the debate on the psychological determinants of international migration by investigating whether, how, and to what extent psychological differences between individuals can help to understand individual migration propensities.

\subsection{Theoretical Considerations and Current State of Research}

Risky behaviours are those whose outcome is not known beforehand; they afford both the opportunity for reward and the possibility of loss or failure (Mata et al. 2018, p. 156). Risk attitude is a well-established construct, used primarily by psychologists and economists in the analysis of risky behaviours. We conceptualise an individual's risk attitude (also called risk preference or risk orientation) as their general willingness to take risks (Dohmen et al. 2011; Mata et al. 2018). People vary in their appetite for risk; risk-averse individuals prefer to avoid risks, whereas risk-affine individuals are willing to take risks or even enjoy doing so.

A further distinction can be drawn between risk and uncertainty. In risky situations, such as a game of roulette, the probabilities of different outcomes are known or knowable. In uncertain situations, such as moving abroad, in contrast, those probabilities are unknown (Williams and Baláž 2012). In most real-life situations, the future is not predictable. Accordingly, the focus of studies in the social sciences tends to be on cases of uncertainty. It seems reasonable to assume that risk-affine individuals will be more likely than risk-averse individuals to engage in uncertain behaviours. Various empirical studies have indeed demonstrated the behavioural consequences of risk attitudes across contexts such as financial investments, careers, 
and health. The tendency to take risks has been shown to correlate with behaviours including educational choices (Obermeier and Schneider 2015), smoking and specific sport and leisure activities (Dohmen et al. 2011), and job mobility (van Huizen and Alessie 2019).

\subsubsection{Risk Attitude and the Propensity to Migrate}

Individual risk attitude has also been suggested to influence the propensity to migrate (Bonin et al. 2009; Huber and Nowotny 2018; Jaeger et al. 2010). People who decide to leave their familiar surroundings to live and work abroad face substantial changes and challenges. Migration tends to be motivated by the aspiration to improve one's living conditions. Success in this endeavour cannot be guaranteed, however. There is always the risk of failure, even if the move is well informed and well planned. Migrants' knowledge of the destination country, its opportunities and conditions, is imperfect, causing uncertainty (Williams and Baláž 2012). Leaving family, friends, and neighbours can result in a loss of instrumental and psychological support, causing further uncertainty. In addition, migrants leave familiar legal frameworks and cultural institutions (e.g., languages and patterns of everyday social interaction) behind them and are often no longer covered by social security provisions (e.g. health insurance). Against this background, it seems reasonable to assume that migrants originating from high-income countries such as Germany, whose decision to migrate is not driven primarily by the aspiration to escape poverty and disadvantage (van Dalen and Henkens 2007), are especially adventurous and risk-loving.

Although Boneva and Frieze (2001) have proposed a 'migrant personality' that might explain why some people decide to migrate while others do not, little is known about the psychological determinants of international migration. As noted above, in the neoclassical economic literature, migration is conceptualised as an investment decision informed by the expected costs and benefits of migration (Massey et al. 1994; Sjaastad 1962). Individuals decide to migrate when the benefits of migration (e.g. a better standard of living) outweigh its costs (e.g., the expenses of moving and setting up a new home, but also social and emotional costs). Both costs and benefits are uncertain, especially when the destination is unfamiliar. Individual risk attitudes may affect the weight that people give to these costs and benefits and thus influence the migration decision. More adventurous and riskloving individuals may be more willing than risk-averse people to accept higher costs in order to improve their chances of success.

To date, only a few studies have empirically analysed the impact of individual risk attitudes on the propensity to migrate. These studies have examined different migrant groups and obtained mixed results. Jaeger et al. (2010) studied internal migrants in Germany. Controlling for a range of demographic characteristics, they found that individuals who were more willing to take risks were more likely to migrate (for similar results, see Bauernschuster et al. 2014). The results of a study 
on the risk attitudes of migrants to Germany suggest the opposite: Bonin et al. (2009) found that first-generation immigrants were, on average, less willing to take risks than German natives. This result needs to be interpreted with caution, however: Immigrants were defined retrospectively by citizenship (and not by actual migration experience), meaning that the analysis was limited to a well-defined but selective group of immigrants. It is possible that more risk-affine migrants had already moved on to other countries.

Another problem with the Bonin et al. (2009) study is that they compared the risk attitudes of migrants with those of the population of the receiving country. Given findings of substantial cross-national variation in risk appetite (Falk et al. 2018), it would make more sense to compare the risk attitudes of migrants with those of compatriots who stayed in the country of origin. A recent study by Huber and Nowotny (2018) attempted to overcome this limitation. Using data from 30 mostly post-communist and emerging countries, they investigated the correlation between migration intention and individual risk attitudes. Across all countries, more riskaffine individuals were more likely to be willing to migrate, whether within the country or abroad. Furthermore, the results suggested that potential emigrants from wealthier countries were particularly adventurous and risk-loving. Likewise, Williams et al. (2018) studied the migration intentions of young adults in Europe. Their findings again identified individual risk attitude as an important determinant of the willingness to migrate. Moreover, they found that this personality trait played a more important role in Germany and UK than in Eastern European countries. Note, however, that both studies investigated migration intentions rather than actual migration behaviour.

Our study was designed to overcome the limitations of these previous analyses. It drew on new data from the German Emigration and Remigration Panel Study (GERPS) in combination with data from the German Socio-Economic Panel Study (SOEP). Our analyses considered actual migration behaviour rather than migration intentions and compared the risk attitudes of German emigrants and remigrants ('movers') with those of the non-mobile population ('stayers').

Research has found consistent differences in risk attitudes along sociodemographic lines. Men tend to be more willing to take risks than women; risk affinity declines with age and is positively correlated with educational level (Dohmen et al. 2011). In addition, the uncertainty of international migration can be expected to decrease as a function of the resources available to an individual: resources like economic, human, and social capital can buffer the possible negative consequences of migration. To exclude the possibility that differences in key sociodemographic or socio-economic characteristics are at the root of differences in risk affinity, we controlled for current age and $\mathrm{age}^{2}$, gender, household composition, labour force status, education, and subjective health status and migration background.

Accordingly, we formulated the following general hypothesis about the risk attitudes of German migrants:

H1 Internationally mobile individuals are more willing to take risks than are nonmobile individuals staying in Germany (controlling for a variety of sociodemographic and socio-economic characteristics). 
In contrast to what is commonly assumed in migration theory, migration is not necessarily a linear movement from one location to a permanent new destination. Remigration to the home country is also an important feature of international migration, as is moving on to another country (Constant and Zimmermann 2013). However, it is unclear whether-and if so, how-risk attitudes affect this kind of circular migration.

Remigration might be assumed to involve less uncertainty than emigration: (potential) remigrants know much more about the living conditions in their country of origin and may still have support networks there (e.g. family and friends). Yet a certain level of risk remains: Remigrants have to leave their workplaces, neighbourhoods, and the social networks they have built up while living abroad. It remains uncertain whether their reintegration in Germany will succeed. We therefore formulated the following hypothesis on the risk attitudes of remigrants:

H2 The risk attitudes of remigrants do not differ from those of emigrants (controlling for a variety of socio-demographic and socio-economic characteristics).

\subsubsection{Risk Attitude and Choice of Where to Move}

Risk attitude might affect not only the decision to migrate but also the choice of where to move. The costs and risks of international migration depend to some extent on the distance between the country of origin and the destination, in both geographical and cultural terms. The further away the destination, the higher the costs of relocating, the more difficult it is to obtain information about the destination in advance, and the greater the challenges of keeping in touch with family and friends back home. Probably more importantly, larger differences in culture, language, institutions, values, and norms require greater adaption. Migrants not only need to learn a new language, they also need to get used to another way of life.

Much research has shown that migration flows decrease with geographical distance, indicating that geographical and cultural differences are a main migration barrier (Belot and Ederveen 2012; Hofstede 2001). Little is known, however, about individual differences in the propensity to migrate to geographically and culturally distant countries. One might expect more adventurous and risk-loving individuals to be more willing to accept (or even actively seek out) cultural differences. The findings of Bauernschuster et al. (2014) on moves within Germany point in this direction, showing that more risk-affine individuals were mobile over longer distances and more likely to cross cultural boundaries within Germany (as measured by historical dialect data). The same can be expected to apply to international migration. To our knowledge, however, no previous study has investigated this relationship.

Geographical and especially cultural distance between countries is hard to define and even harder to measure in a valid manner. As a first, rough approximation, we distinguished between countries neighbouring Germany, other European countries, and non-European countries. The neighbouring countries were further divided in 
two groups: (primarily or partly) German-speaking countries (Austria, Switzerland, and Luxembourg) and (primarily) non-German-speaking countries (France, Belgium, Netherlands, Denmark, Poland, and the Czech Republic). We would expect the costs of migration to (partly) German-speaking neighbouring countries to be lowest, followed by non-German speaking neighbouring countries, other European countries, and finally non-European countries. We worked on the assumption that European countries are culturally closer to Germany than are non-European countries not least due to the process of European integration, which offers a common economic, political, and legal institutional framework.

Against this background, we formulated the following hypothesis:

H3 Migrants to geographically and culturally more distant countries are more riskaffine than are migrants to geographically and culturally less distant countries.

The costs and risks of international migration can be minimized in various ways. Language competence is a key factor here. Migrants with at least a basic knowledge of the language spoken in the destination country should find it easier to adapt and settle in. Those with poor or no language skills face higher cultural barriers and thus need to be more risk-affine. Previous migration experience can also be expected to reduce uncertainty; experienced migrants are more aware of the challenges and difficulties of international migration. We therefore hypothesized the following:

H4 Migrants with no or low language competence are more risk-affine than migrants with good language competence; migrants with no previous migration experience are more risk-affine than migrants with previous migration experience.

The costs and insecurity associated with remigration depend primarily on whether migrants have maintained connections to the country of origin during their stay abroad. Remigration should be easier for migrants who have kept up family and friendship ties and stayed informed about developments in their country of origin. We captured these connections to the home country by remigrants' emotional attachment to Germany and the duration of stay abroad. We hypothesized the following:

H5 Remigrants who stayed abroad for longer are more risk-affine than are those who were not away for so long; remigrants who feel less attached to Germany are more risk-affine than those who still have friendship ties with Germany.

\subsection{Data and Methods}

We drew on two data sources: the German Emigration and Remigration Panel Study (GERPS), which assesses internationally mobile Germans, and the German SocioEconomic Panel Study (SOEP), which covers Germany's non-mobile population. GERPS is based on a random sample drawn from local population registers and covers 20-70 year old German nationals who either emigrated from or remigrated 
to Germany between July 2017 and June 2018 (see Ette et al. 2021 in this volume). We use data from GERPS wave 1, which contains information on 11,897 individuals (4928 emigrants and 6969 remigrants). The German Socio-Economic Panel Study (SOEP) is a wide-ranging representative multi-cohort study of the population living in Germany. Every year, around 30,000 persons in about 15,000 households are surveyed (Goebel et al. 2019). The SOEP provides a control sample of internationally non-mobile Germans, allowing us to assess differences in risk attitudes between movers and stayers. We used data from 2017 (v34), limiting the dataset to German citizens. We also excluded all individuals who had moved 20 kilometers or more within Germany between 2015 and 2017, resulting in a study sample of 20,134 German stayers.

Individual risk attitudes were assessed in terms of self-reported general willingness to take risks. Respondents to both GERPS and SOEP were asked: "Are you generally a person who is willing to take risks or do you try to avoid taking risks?" Responses were given on a scale from 0 ('not at all willing to take risks') to 10 ('very willing to take risks'). This self-report measure has proved to be a valid indicator of risk attitude that is strongly associated with actual behaviour (Dohmen et al. 2011; Mata et al. 2018). We estimated multivariate OLS regressions on individual risk attitudes; as control variables, we included age and age2, gender, household composition, labour force status, education, subjective health status, and migration background, and different more migration specific explanatory variables such as self-rated language competence, and previous migration experience. Table 5.1 reports the descriptive statistics for the variables included in our analyses; Table 5.2 provides descriptive statistics for further independent variables included in later analyses (regressions of geographical/cultural distance on risk attitude).

\subsection{Results}

Figure 5.1 shows the distribution of the general willingness to take risks among German emigrants, remigrants, and stayers. For the stayers, the findings are consistent with the results of other studies (e.g. Dohmen et al. 2011, p. 527). Risk attitude was distributed widely across the entire scale, but clearly peaked at the mid-point 5 . The picture emerging for movers is completely different: they were much more willing to take risks than stayers, and the distributions for emigrants and remigrants were highly congruent, peaking at point 7. Table 5.3 confirms these descriptive findings: Under statistical control for key socio-demographic and socio-economic variables, both emigrants and remigrants reported significantly higher risk affinity than stayers (Model 1). This finding supports our first hypothesis, confirming that internationally mobile individuals are more willing to take risks than are their counterparts who stayed in Germany.

Furthermore, there was no significant difference in the risk attitudes of emigrants and remigrants (Model 2 in Table 5.3). Individuals who returned to Germany were not more or less risk-affine than German emigrants who had recently moved abroad. 
Table 5.1 Descriptive statistics used in mover-stayer comparisons

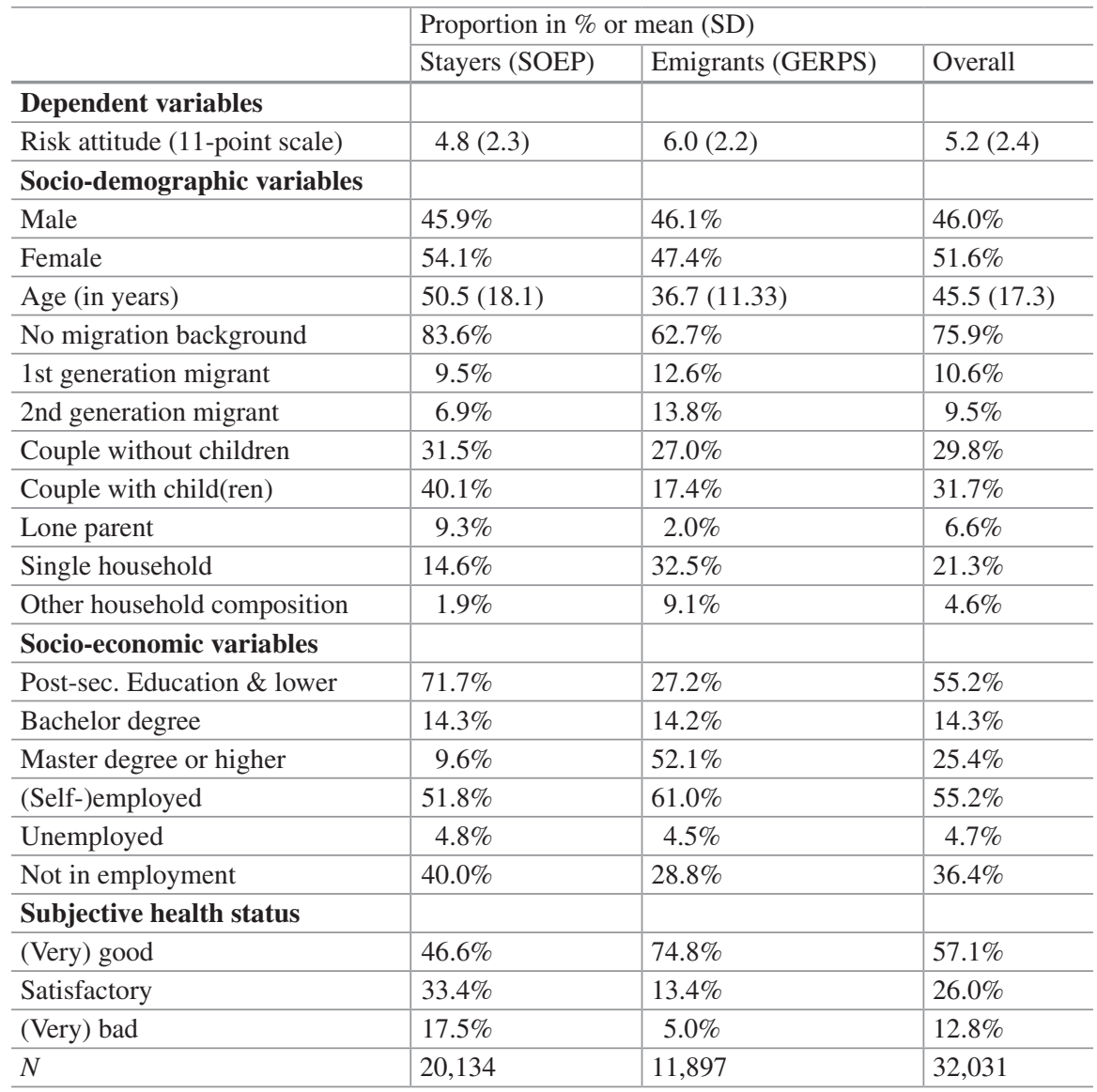

Sources: GERPSw1, SOEP2017

This finding suggests that individual risk attitude affects the decision to emigrate but does not have an additional impact on the decision to remigrate. This may be because remigration is less risky than emigration: remigrants are much more knowledgeable about the living conditions in their country of origin and can often rely on an established support network (e.g. family members) when returning to Germany.

Finally, we ran a separate estimation for German stayers only (Model 3) to compare patterns of correlation between the control variables and risk attitudes in this group and in the group of German migrants (Model 2). Overall, the pattern of coefficients for the stayers (Model 3) was similar to that observed in previous studies (e.g. Dohmen et al. 2011; Halek and Eisenhauer 2001): Females had lower risk attitudes than men; willingness to take risks declined with age and was positively correlated with educational level. In addition, couples with children were less riskaffine than were individuals living in single households. Finally, there was a significant negative relationship between health and risk attitude. 
Table 5.2 Descriptive statistics used in analyses on geographical/cultural distance

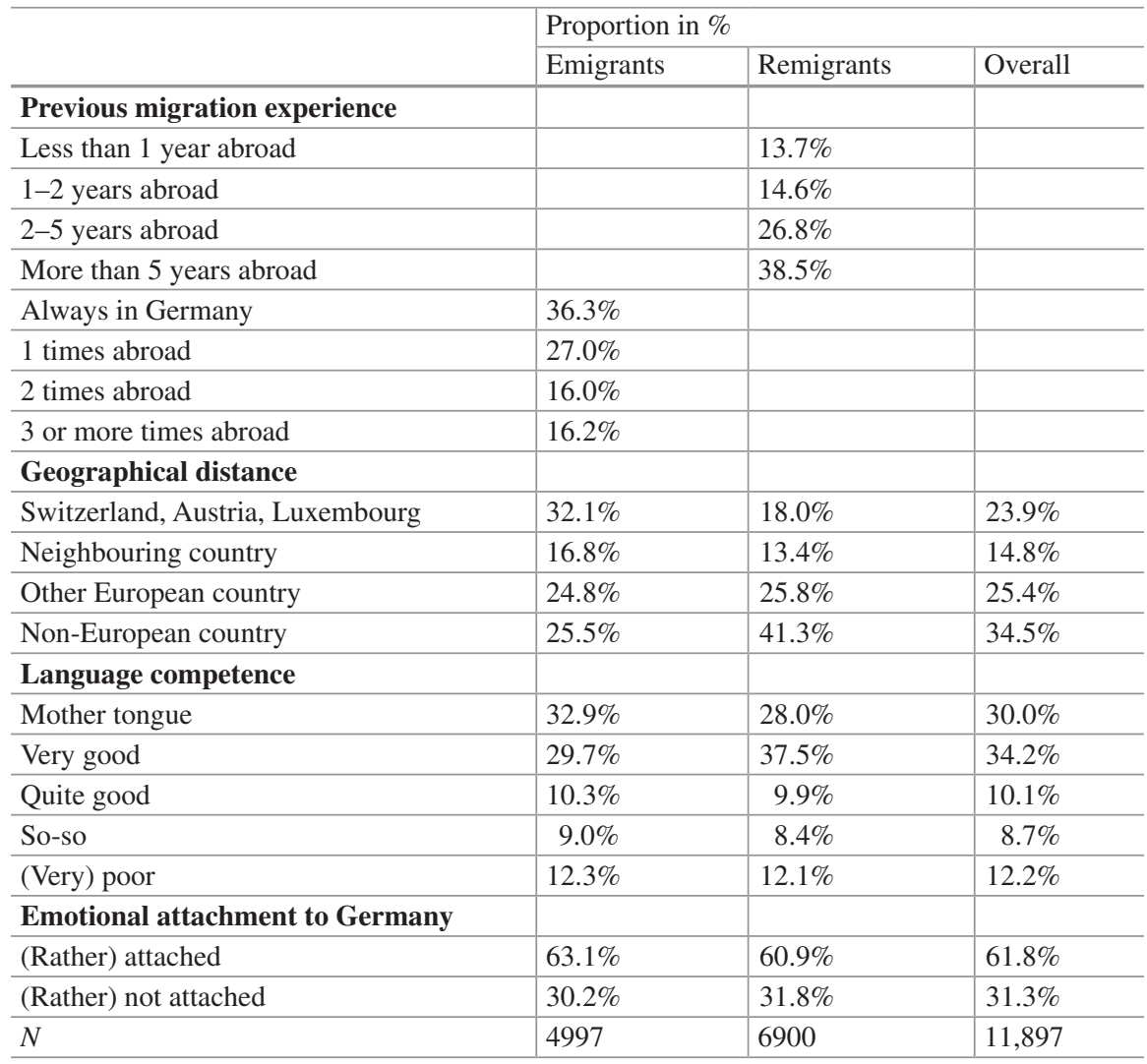

Source: GERPSw1

Comparison with the estimation for internationally mobile Germans (Model 2) shows that migrants' risk attitudes only partly followed the patterns observed for stayers. As for stayers, we found a negative relationship between health and willingness to take risks, and women had significantly lower risk attitudes than men. However, no age or education effects emerged. The model fit of Model 2 was considerably lower than that of Model 3 (R2: 0.019 vs. 0.076), indicating that our standard socio-economic and socio-demographic control variables correlated much better with stayers' risk attitudes than with movers'.

We now turn to the relationship between migrants' risk attitude and their choice of where to move. We expected more risk-affine migrants to be more likely to move to geographically/culturally more distant countries. As described above, we distinguished between German-speaking neighbouring countries (as the reference group), non-German-speaking neighbouring countries, other European countries, and nonEuropean countries, assuming this differentiation to capture increasing geographical/cultural distance. 


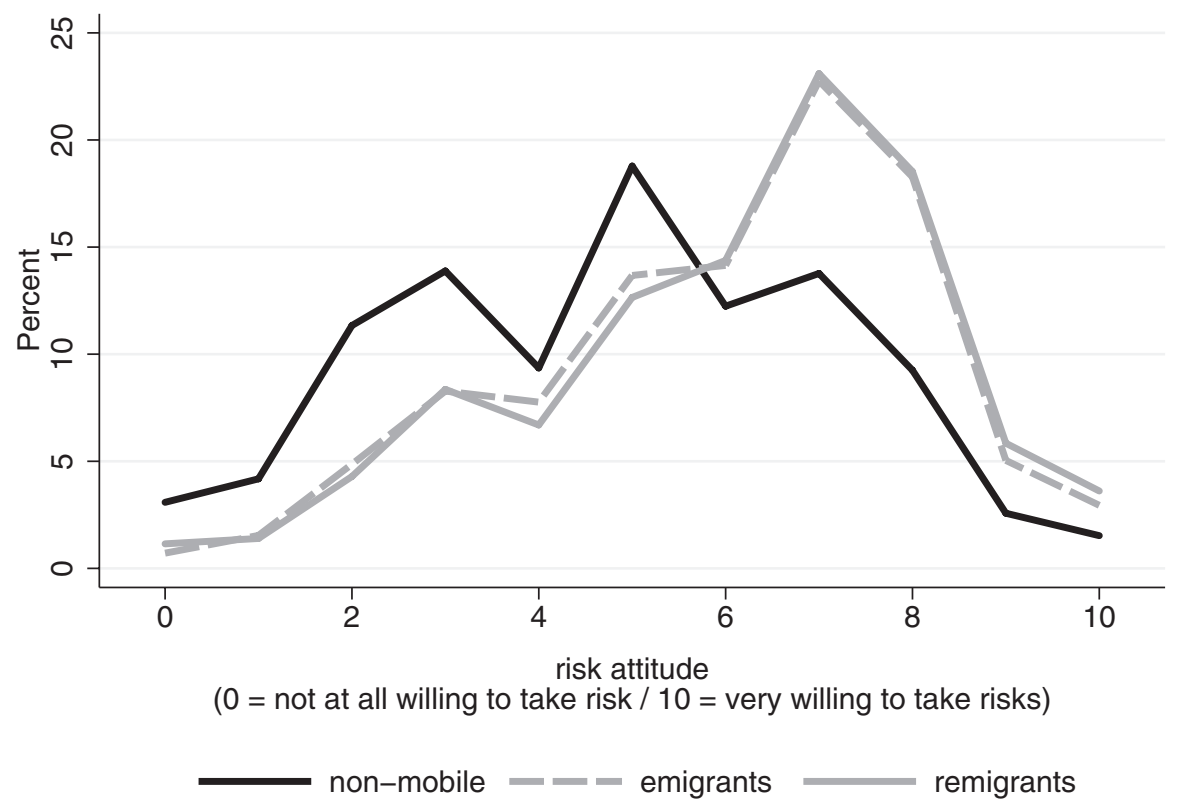

Fig. 5.1 Distribution of general willingness to take risks for German stayers, emigrants, and remigrants. (Sources: GERPSw1, SOEP2017)

Table 5.4 displays the results of regressions of country of destination on individual risk attitude separately for emigrants and remigrants, controlling for the variables analysed in Table 5.3. For emigrants, risk attitude was positively associated with geographical/cultural distance: Emigrants moving to non-European countries were significantly more risk-affine than those moving to German-speaking neighbouring countries. The same held for emigrants to European countries that do not neighbour Germany. There was, however, no significant difference in the risk attitudes of emigrants to German- versus non-German-speaking neighbouring countries. This finding suggests that language does not seem to be the main migration barrier for German emigrants. Note, however, that the lion's share of German emigration was to German-speaking neighbouring countries (see Ette and Erlinghagen 2021). For remigrants, we again observed a positive relationship between risk attitude and geographical/cultural distance. Remigrants returning from non-European countries reported highly significantly higher risk attitudes. These results confirm our hypothesis that geographical/cultural distance of the destination country is positively related to risk-affinity.

In a final step, we investigated the role of other factors that might increase or decrease the costs of international migration (Table 5.5): language competence, previous migration experience, duration of stay abroad, and emotional attachment to Germany. We assumed that speaking the language of the destination country reduces feelings of insecurity. Consequently, we expected emigrants with good language skills to report a lower willingness to take risks than emigrants with no or poor 
Table 5.3 Coefficients and standard errors (in parentheses) of the OLS regressions on migration and willingness to take risks

\begin{tabular}{l|l|l|l}
\hline & Model (1): Full model & Model (2): Movers & Model (3): Stayers \\
\hline Stayers & Ref. & - & \\
\hline Emigrants & $0.876^{* * *}$ & ref. & \\
\hline Remigrants & $(0.046)$ & - & \\
\hline & $0.976^{* * *}$ & 0.081 & \\
\hline Age & $(0.042)$ & $(0.043)$ & \\
\hline & -0.001 & 0.006 & $-0.021^{* * *}$ \\
\hline Age $^{2}$ & $(0.005)$ & $(0.010)$ & $(0.006)$ \\
\hline & $-0.000^{*}$ & 0.000 & 0.000 \\
\hline Female (ref. male) & $(0.000)$ & $(0.000)$ & $(0.000)$ \\
\hline & $-0.714^{* * *}$ & $-0.311^{* * *}$ & $-0.896^{* * *}$ \\
\hline
\end{tabular}

Household composition (ref. single household)

\begin{tabular}{l|l|l|l}
\hline Couple without children & $-0.101^{* *}$ & $-0.259^{* * *}$ & -0.010 \\
\hline Couple with child(ren) & $(0.037)$ & $(0.053)$ & $(0.051)$ \\
\hline & $-0.145^{* * *}$ & $-0.290^{* * *}$ & $-0.147^{* *}$ \\
\hline Lone parent & $(0.039)$ & $(0.062)$ & $(0.054)$ \\
\hline & 0.013 & -0.078 & 0.009 \\
\hline Other household composition & $(0.059)$ & $(0.148)$ & $(0.070)$ \\
\hline & $0.143 *$ & 0.127 & $0.285^{*}$ \\
\hline & $(0.066)$ & $(0.076)$ & $(0.126)$
\end{tabular}

Labour force status (ref. (self-)employed)

\begin{tabular}{l|l|l|l}
\hline Unemployed & $0.248 * * *$ & 0.117 & $0.273 * * *$ \\
\hline Not in employment & $(0.062)$ & $(0.101)$ & $(0.078)$ \\
\hline & -0.056 & $-0.195 * * *$ & -0.014 \\
\hline & $(0.033)$ & $(0.050)$ & $(0.044)$
\end{tabular}

Highest educ. Qualification (ref. post-sec. Education \& lower)

\begin{tabular}{l|l|l|l}
\hline Bachelor degree & $0.120^{* *}$ & 0.091 & $0.130 * *$ \\
\hline Master degree or higher & $(0.038)$ & $(0.068)$ & $(0.047)$ \\
\hline & -0.040 & -0.026 & -0.018 \\
\hline & $(0.036)$ & $(0.050)$ & $(0.056)$
\end{tabular}

Migration background (ref. no migration background)

\begin{tabular}{|c|c|c|c|}
\hline 1st generation migrant & -0.033 & $-0.198 * *$ & 0.099 \\
\hline & $(0.041)$ & $(0.061)$ & $(0.055)$ \\
\hline \multirow[t]{2}{*}{ 2nd generation migrant } & $0.221 * * *$ & $0.116^{*}$ & $0.254 * * *$ \\
\hline & $(0.046)$ & $(0.059)$ & $(0.070)$ \\
\hline \multicolumn{4}{|c|}{ Subjective health status (ref. (very) good) } \\
\hline \multirow[t]{2}{*}{ Satisfactory } & $-0.263 * * *$ & $-0.291 * * *$ & $-0.237 * * *$ \\
\hline & $(0.032)$ & $(0.060)$ & $(0.038)$ \\
\hline \multirow[t]{2}{*}{ (Very) bad } & $-0.603 * * *$ & $-0.321 * * *$ & $-0.622 * * *$ \\
\hline & $(0.042)$ & $(0.095)$ & $(0.047)$ \\
\hline \multirow[t]{2}{*}{ Constant } & $5.791 * * *$ & $6.163 * * *$ & $6.393 * * *$ \\
\hline & $(0.108)$ & $(0.211)$ & $(0.145)$ \\
\hline Observations & 29,852 & 10,466 & 19,386 \\
\hline$R^{2}$ & 0.116 & 0.019 & 0.076 \\
\hline
\end{tabular}

Sources: GERPSw1, SOEP2017, *p $<0.05, * * p<0.01, * * * p<0.001$ 
Table 5.4 Coefficients (and standard errors) of the OLS regressions of destination on risk attitude

\begin{tabular}{l|l|l}
\hline & Emigrants & Remigrants \\
\hline Switzerland, Austria, Luxembourg & Ref. & Ref. \\
\hline Other neighbouring country & -0.024 & -0.130 \\
\hline & $(0.093)$ & $(0.097)$ \\
\hline Other European country & $0.222^{* *}$ & 0.051 \\
\hline & $(0.083)$ & $(0.082)$ \\
\hline Non-European country & $0.446^{* * *}$ & $0.313^{* * *}$ \\
\hline Constant & $(0.083)$ & $(0.077)$ \\
\hline & $5.855^{* * *}$ & $6.155^{* * *}$ \\
\hline Observations & $(0.311)$ & $(0.278)$ \\
\hline$R^{2}$ & 4639 & 6358 \\
\hline Bot mos & 0.032 & 0.025 \\
\hline
\end{tabular}

Both models control for age, age ${ }^{2}$, gender, family composition, labour force status, highest educational qualification, migration background, and subjective health status. Source: GERPSw1 $* p<0.05, * * p<0.01, * * * p<0.001$

language skills. Indeed, multivariate results suggest that emigrants with lower than mother tongue skills, are more willing to take risks than native speakers. There are, however, no differences between those who report good, mediocre, and poor skills. Pairwise comparisons (not reported in Table 5.5) corroborate the finding that each single category is associated with higher risk propensity than the reference category of native speakers. Thus, all non-native speaking emigrants seems to have a significantly higher appetite for risk than native speakers do.

Some correlations between the number of previous stays abroad (of 4 months or more) and risk attitudes also emerged, but in an unexpected direction. Instead of the expected negative correlation, the willingness to take risks increased with the number of previous stays abroad. Within the narrow economic theory of migration, this finding could be interpreted as evidence that voluntary emigration from high-income countries like Germany is only partly motivated by the aspiration to better one's living conditions or attributable to available resources; rather, it seems to be simply a matter of risk appetite. Thus, (repeated) emigration seems to be a matter of personality and an expression of a more adventurous lifestyle.

For remigrants, we considered emotional attachment to Germany and duration of stay abroad as factors that could potentially affect the insecurity associated with a return to Germany. As expected, remigrants who felt less attached to Germany were more risk-affine than those who felt more attached. This could be because the risks of remigration are lower for those who feel attached to Germany. For the same reasons, we predicted that the risks of remigration would increase as a function of the length of the stay abroad. However, the data did not confirm that remigrants who had stayed abroad for longer were also more risk-affine than those who were not away for so long. If anything, the opposite was true: there was a weak but significant negative correlation between risk attitude and a length of stay abroad exceeding 3 years. 
Table 5.5 Coefficients and standard errors (in brackets) of the OLS regressions on language competence, previous migration experience, emotional attachment to Germany, and duration of stay abroad on risk attitude

\begin{tabular}{|c|c|c|}
\hline & Emigrants & Remigrants \\
\hline \multicolumn{3}{|l|}{ Language competence } \\
\hline Mother tongue & Ref. & \\
\hline \multirow[t]{2}{*}{ Very good } & $0.289^{* * *}$ & \\
\hline & $(0.077)$ & \\
\hline \multirow[t]{2}{*}{ Quite good } & 0.203 & \\
\hline & $(0.108)$ & \\
\hline \multirow[t]{2}{*}{ So-so } & $0.265^{*}$ & \\
\hline & $(0.114)$ & \\
\hline \multirow[t]{2}{*}{ (Very)Poor } & $0.296^{* *}$ & \\
\hline & $(0.102)$ & \\
\hline \multicolumn{3}{|l|}{ Previous migration experience } \\
\hline Always in Germany & Ref. & \\
\hline \multirow[t]{2}{*}{1 time abroad $\geq 4$ months } & $0.180^{*}$ & \\
\hline & $(0.080)$ & \\
\hline \multirow[t]{2}{*}{2 times abroad $\geq 4$ months } & $0.301 * *$ & \\
\hline & $(0.094)$ & \\
\hline \multirow[t]{2}{*}{3 or more times abroad $\geq 4$ months } & $0.578 * * *$ & \\
\hline & $(0.095)$ & \\
\hline \multicolumn{3}{|l|}{ Emotional attachment to Germany } \\
\hline Rather attached & & Ref. \\
\hline \multirow[t]{2}{*}{ Rather not attached } & & $0.198^{* * *}$ \\
\hline & & $(0.058)$ \\
\hline \multicolumn{3}{|l|}{ Duration of stay abroad } \\
\hline$<1$ year & & Ref. \\
\hline \multirow[t]{2}{*}{$1-2$ years } & & -0.085 \\
\hline & & $(0.102)$ \\
\hline \multirow[t]{2}{*}{$3-5$ years } & & $-0.222^{*}$ \\
\hline & & $(0.093)$ \\
\hline \multirow[t]{2}{*}{ More than 5 years } & & $-0.196^{*}$ \\
\hline & & $(0.090)$ \\
\hline \multirow[t]{2}{*}{ Constant } & $5.717^{* * *}$ & $6.157^{* * *}$ \\
\hline & $(0.310)$ & $(0.277)$ \\
\hline Observations & 4639 & 6358 \\
\hline$R^{2}$ & 0.037 & 0.022 \\
\hline
\end{tabular}

Both models control for age, age ${ }^{2}$, gender, family composition, labour force status, highest educational qualification, migration background, and subjective health status. Sources: GERPSw1, SOEP 2017

$* p<0.05, * * p<0.01, * * * p<0.001$ 


\subsection{Summary and Conclusion}

This study with German respondents examined whether the risk attitudes of internationally mobile individuals ('movers') differed significantly from those of nonmobile individuals ('stayers'), and whether there were significant differences in the risk attitudes of emigrants and remigrants. The study also asked whether the willingness to take risks was associated with the geographical/cultural distance to the destination country.

We were able to overcome the limitations of previous studies-i.e., focusing on migration intentions rather than actual moves; comparing migrants' risk attitudes with those of the native population-by analysing data from the German Emigration and Remigration Panel Study (GERPS) in combination with data from the German Socio-Economic Panel Study (SOEP). We considered actual moves rather migration intentions and compared the individual risk attitudes of German emigrants and remigrants ('movers') with those of the non-mobile German population ('stayers').

Our results show that movers were more willing to take risks than stayers. Contrary to our expectations, there was no difference in the risk attitudes of emigrants and remigrants. Migrants who moved to geographically/culturally more distant countries were more risk-affine than those who moved to less distant countries. Interestingly, migrants' risk affinity increased with the number of previous emigration episodes. Taken together, our results suggest that international mobility of citizens of high-income countries seems to be a matter of personality and an expression of a more adventurous lifestyle-particularly for those moving (repeatedly) to distant non-European countries.

Although our findings provide interesting new evidence on the relationship between risk attitudes and international migration, at least two limitations warrant consideration. First, we relied on risk attitudes reported shortly after migrants had arrived in their new home. It is possible that individual risk attitudes change during the migration process. In that case, our finding of higher risk-affinity among movers would be a (temporary) effect of migration itself. Specifically, increased willingness to take risks after migration would not reflect psychological differences between movers and stayers, but would be an effect of increased self-esteem through recent migration events. It will be possible to investigate such changes in individual risk attitudes during the migration process when data from the third wave of GERPS are available. Second, our measure of cultural distance through geographical distance is a very rough indicator. Future research should include more sophisticated, regional indexes of cultural distance (see Hofstede 2001). However, beside these limitations and given the scarce empirical evidence on the relationship between international migration and risk attitudes, our study contributes to the debate about the psychological determinants of international migration. 


\section{References}

Bauernschuster, S., Falck, O., Heblich, S., Suedekum, J., \& Lameli, A. (2014). Why are educated and risk-loving persons more mobile across regions? Journal of Economic Behavior \& Organization, 98, 56-69.

Belot, M., \& Ederveen, S. (2012). Cultural barriers in migration between OECD countries. Journal of Population Economics, 25(3), 1077-1105.

Boneva, B. S., \& Frieze, I. H. (2001). Toward a concept of a migrant personality. Journal of Social Issues, 57(3), 477-491.

Bonin, H., Constant, A., Tatsiramos, K., \& Zimmermann, K. F. (2009). Native-migrant differences in risk attitudes. Applied Economics Letters, 16(15), 1581-1586.

Constant, A., \& Zimmermann, K. F. (Eds.). (2013). International handbook on the economics of migration. Cheltenham: Edward Elgar.

Dohmen, T., Falk, A., Huffman, D., Sunde, U., Schupp, J., \& Wagner, G. G. (2011). Individual risk attitudes: measurement, determinants and behavioral consequences. Journal of the European Economic Association, 9(3), 522-550.

Erlinghagen, M., Stegmann, T., \& Wagner, G. G. (2009). Deutschland ein Auswanderungsland? DIW Wochenbericht, 39(2009), 663-669.

Ette, A., Décieux, J. P., Erlinghagen, M., Guedes Auditor, J., Sander, N., Schneider, N. F., \& Witte, N. (2021). Surveying across borders: The experiences of the German emigration and remigration panel study. In M. Erlinghagen, A. Ette, N. F. Schneider, \& N. Witte (Eds.), The global lives of German migrants. Consequences of international migration across the life course. Cham: Springer.

Ette, A., \& Erlinghagen, M. (2021). Structures of German emigration and remigration: Historical developments and demographic patterns. In M. Erlinghagen, A. Ette, N. F. Schneider, \& $\mathrm{N}$. Witte (Eds.), The global lives of German migrants. Consequences of international migration across the life course. Cham: Springer.

Falk, A., Becker, A., Dohmen, T., Enke, B., Huffman, D., \& Sunde, U. (2018). Global evidence on economic preferences*. The Quarterly Journal of Economics, 133(4), 1645-1692.

Fischhoff, B., Goitein, B., \& Shapira, Z. (1981). Subjective expected utility: A model of decisionmaking. Journal of the American Society for Information Science, 32(5), 391-399.

Fishburn, P. C. (1981). Subjective expected utility: A review of normative theories. Theory and Decision, 13(2), 139-199.

Goebel, J., Grabka, M. M., Liebig, S., Kroh, M., Richter, D., Schröder, C., \& Schupp, J. (2019). The German Socio-Economic Panel (SOEP). Jahrbücher für Nationalökonomie und Statistik, 239(2), 345-360.

Guedes Auditor, J., \& Erlinghagen, M. (2021). The happy migrant? Emigration and its impact on social wellbeing. In M. Erlinghagen, A. Ette, N. F. Schneider, \& N. Witte (Eds.), The global lives of German migrants. Consequences of international migration across the life course. Cham: Springer.

Halek, M., \& Eisenhauer, J. G. (2001). Demography of risk aversion. The Journal of Risk and Insurance, 68(1), 1.

Hofstede, G. (2001). Culture's consequences: Comparing values, behaviors, institutions, and organizations across nations (2nd ed.). Thousand Oaks [u.a.]: SAGE Publ.

Huber, P., \& Nowotny, K. (2018). Risk aversion and the willingness to migrate in 30 countries. Wien: Österreichisches Institut für Wirtschaftsforschung.

Jaeger, D. A., Dohmen, T., Falk, A., Huffman, D., Sunde, U., \& Bonin, H. (2010). Direct evidence on risk attitudes and migration. Review of Economics and Statistics, 92(3), 684-689.

Lindenberg, S., \& Frey, B. S. (1993). Alternatives, frames, and relative prices: A broader view of rational choice theory. Acta Sociologica, 36(3), 191-205. 
Massey, D. S., Arango, J., Hugo, G., Kouaouci, A., Pellegrino, A., \& Taylor, J. E. (1994). An evaluation of international migration theory: The North American case. Population and Development Review, 20(4), 699.

Mata, R., Frey, R., Richter, D., Schupp, J., \& Hertwig, R. (2018). Risk preference: A view from psychology. Journal of Economic Perspectives, 32(2), 155-172.

Obermeier, V., \& Schneider, T. (2015). Educational choice and risk preferences: How important is relative vs. individual risk preference? Journal for Educational Research Online, 7(7), 99-128.

Ormel, J., Lindenberg, S., Steverink, N., \& Verbrugge, L. M. (1999). Subjective well-being and social production functions. Social Indicators Research, 46(1), 61-90.

Sjaastad, L. A. (1962). The costs and returns of human migration. Journal of Political Economy, 70(5), 80-93.

van Dalen, H. P., \& Henkens, K. (2007). Longing for the good life: Understanding emigration from a high-income country. Population and Development Review, 33(1), 37-65.

van Huizen, T., \& Alessie, R. (2019). Risk aversion and job mobility. Journal of Economic Behavior \& Organization, 164, 91-106.

Williams, A. M., \& Baláž, V. (2012). Migration, risk, and uncertainty: theoretical perspectives. Population, Space and Place, 18(2), 167-180.

Williams, A. M., Jephcote, C., Janta, H., \& Li, G. (2018). The migration intentions of young adults in Europe: A comparative, multilevel analysis. Population, Space and Place, 24(1), e2123.

Witte, N., \& Guedes Auditor, J. (2021). Affluent lives beyond the border? Individual wage change through migration. In M. Erlinghagen, A. Ette, N. F. Schneider, \& N. Witte (Eds.), The global lives of german migrants. Consequences of international migration across the life course. Cham: Springer.

Open Access This chapter is licensed under the terms of the Creative Commons Attribution 4.0 International License (http://creativecommons.org/licenses/by/4.0/), which permits use, sharing, adaptation, distribution and reproduction in any medium or format, as long as you give appropriate credit to the original author(s) and the source, provide a link to the Creative Commons license and indicate if changes were made.

The images or other third party material in this chapter are included in the chapter's Creative Commons license, unless indicated otherwise in a credit line to the material. If material is not included in the chapter's Creative Commons license and your intended use is not permitted by statutory regulation or exceeds the permitted use, you will need to obtain permission directly from the copyright holder.

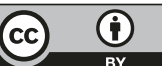

